\title{
A horta como laboratório vivo para trabalhar a interdisciplinaridade no ensino médio
}

\author{
The garden is used as a life laboratory to perform interdisciplinary studies in high school
}

Marisa Meneses Leal ${ }^{1}$, Rosana Santos de Moraes $^{2}$, Bianca Motta Dolianitis 3 , Gabriel Cogo Pagliarin 4 , Jaqueline Rambo Anschau ${ }^{5}$, Janessa Aline Zappe ${ }^{6}$ e Viviane Dal-Souto Frescura ${ }^{7}$

${ }^{1}$ Laboratório de processos Biológicos (LAPROBIO), Universidade Federal de Santa Maria - Campus Cachoeira do Sul, Cachoeira do Sul, Brasil

viviane.frescura@ufsm.br

${ }^{2}$ Universidade Federal de Santa Maria - Campus Cachoeira do Sul, Cachoeira do Sul, Brasil

rosana-moraes95@hotmail.com; viviane.frescura@ufsm.br; viviane.frescura@ufsm.br; viviane.frescura@ufsm.br; jalinez@hotmail.com; viviane.frescura@ufsm.br

\section{Resumo}

Atualmente a educação passa por um processo de reestruturação e a interdisciplinaridade é fundamental para minimizar os limites existentes entre as disciplinas do Ensino Médio. A origem da interdisciplinaridade está nas transformações dos modos de produzir a ciência e de perceber a realidade. Nesse sentido, a horta escolar pode ser um meio de relacionar os conhecimentos das diversas disciplinas. Com este trabalho de extensão objetivou-se implantar uma horta na Escola Estadual de Ensino Médio Ruy Barbosa, no municipio de Novo Cabrais - RS, com a finalidade de promover ações interdisciplinares. Antes da implantação da horta foi realizada palestra direcionada aos alunos e professores. Foi escolhido um local ocioso e com potencial para o cultivo de hortaliças, onde foi implantada a horta. Foram cultivadas alface, rúcula, tomate, mandioca, beterraba, batata-doce, milho pipoca, feijão, moranga japonesa, funcho, abóbora, rabanete e almeirão, dentre outras espécies. Dentre as atividades interdisciplinares para serem trabalhadas no Ensino Médio destacam-se o cálculo da produção total de cada espécie cultivada na horta, estudo dos centros de origem de cada espécie, nomes científicos das espécies cultivadas, uso de inseticidas naturais e adubo orgânico, povos de diferentes regiões que utilizam as espécies cultivadas na alimentação elou como plantas medicinais.

Palavras-chave: Hortas escolares; Atividades interdisciplinares; Interdisciplinar

\section{Abstract}

Nowadays, education undergoes a process of restructuring and interdisciplinarity is fundamental to minimize the existing limits between the disciplines of High School. The origin of interdisciplinarity lies in the transformations of the ways of producing science and of perceiving reality. In this sense, the school garden can be a way to relate the knowledge of the various disciplines. With this extension work, the objective was to implement a vegetable garden at the Ruy Barbosa State High School, in the municipality of Novo Cabrais - RS, in order to promote interdisciplinary actions. Before the implementation of the garden, a lecture was given to students and teachers. It was chosen an idle place with potential for the cultivation of vegetables, where the vegetable garden was implanted. Lettuce, arugula, tomato, cassava, beet, sweet potato, popcorn, beans, Japanese moranga, fennel, pumpkin, radish and almeirão, among others crops. Among the interdisciplinary activities to be worked in High School are the calculation of the total production of each species cultivated in the garden, study of the centers of origin of each species, scientific names of the cultivated species, use of natural insecticides and organic fertilizer, regions that use the species grown in food and / or as medicinal plants. 


\section{Introdução}

O homem cada vez mais deve ser preocupar com a saúde, seu bem estar e com o meio onde vive. Dessa forma, tornase necessário trabalhar esses temas na escola, pois neste período os estudantes estão formando seus hábitos e suas opiniões diante de diferentes questões, difíceis de serem modificadas na vida adulta.

No atual sistema de ensino brasileiro a organização em disciplinas cria barreiras entre os conhecimentos, o que dificulta a aprendizagem de temas conjuntos (MORIN, 2000). Nesse sentido, seria interessante promover a conexão entre duas ou mais disciplinas, para possibilitar a comunicação desde ideias simples até aquelas mais aprimoradas e permitir a vinculação entre professores e alunos para um objetivo em comum.

Assim, a interdisciplinaridade surge para minimizar as barreiras existentes entre as disciplinas e caracteriza-se pela atitude de busca, de sintonia diante do conhecimento, de acordo e de inclusão (FAZENDA, 2008). Entretanto, para que se consiga promover a interdisciplinaridade é preciso sintonia e reciprocidade entre professores e alunos.

No entanto, mesmo a interdisciplinaridade trazendo muitos benefícios aos envolvidos, as escolas ainda apresentam muitas dificuldades em aplicar na prática projetos interdisciplinares: pela dificuldade em compreender o seu real significado ou falta de espaços laborais para praticá-la.

A interdisciplinaridade é o entendimento das disciplinas nas mais diversas áreas, porém, com os recursos de ensino e aprendizagem ampliados, inovadores e dinâmicos (PAVIANI, 2008). Através dessa metodologia, surge uma nova forma de ensinar e de aprender, pois se recorre a um saber diretamente útil e utilizável para resolver problemas sociais e contemporâneos (BRASIL,2002). Dessa forma, no Ensino Médio, muitos são os espaços que possibilitam o trabalho interdisciplinar, e um desses espaços pode ser a horta escolar. Segundo Campioto (2015), os projetos interdisciplinares tornam o processo de ensino e aprendizagem mais dinâmico, motivador e interessante, tanto para o aluno quanto para o professor. O referido autor também implantou uma horta em uma escola de Ensino Médio. Os resultados do desenvolvimento do projeto mostraram que, com o trabalho na horta, os alunos da escola passaram a ter mais interesse pelos conteúdos. A horta, portanto, pode se tornar uma ferramenta muito eficaz na formação integral do estudante.

A escolha da horta como ferramenta para trabalhar a interdisciplinaridade da-se pelo fato de as hortas escolares serem ações que envolvem a comunidade escolar e local, possibilitam trabalhar assuntos como segurança alimentar, sustentabilidade além de serem um espaço para trabahar os conteúdos programáticos das diferentes disciplinas em teoria e prática.

Nesse sentido, objetivou-se implantar uma horta na Escola Estadual de Ensino Médio Ruy Barbosa, no município de Novo Cabrais - RS, com a finalidade de promover a interdisciplinaridade no Ensino Médio. A partir da implantação da horta, a escola terá um espaço para trabalhar a interdisciplinaridade, de acordo com seus projetos e com as necessidades da comundiade escolar.

\section{Material e métodos}

A horta foi implantada na Escola Estadual de Ensino Médio Ruy Barbosa, localizada no município de Novo Cabrais, Rio Grande do Sul. A escola pertence à $24^{\mathrm{a}}$ Coordenadoria Regional de Educação do Rio Grande do Sul (24 $\left.{ }^{\mathrm{a}} \mathrm{CRE}-\mathrm{RS}\right)$. A escola possui noventa alunos divididos entre seis turmas do Ensino Médio nos turnos da tarde e da noite e quinze professores e funcionários. Essa horta faz parte do projeto de extensão Horta Viva na Escola, que acontece desde 2017 (COGO et al., 2017).

A primeira visita realizada na escola ocorreu no primeiro semestre de 2017, com a finalidade de conhecer a área que seria disponibilizada para a implantação da horta. Posteriormente, em outra visita, foi ministrada uma palestra com o tema "Importância das hortas escolares". Participaram da palestra alunos e servidores da escola. 
O início da construção da horta foi em agosto de 2017, com a gradagem da área e montagem dos canteiros. Além disso, nesse mesmo período o espaço com as medidas de onze metros de comprimento por oito metros de largura foi cercado. Durante essas atividades pessoas da comunidade auxiliaram e tornaram possível a implantação da horta na escola.

Foram plantadas diversas culturas em setembro de 2017: alface, radite, rúcula. cebola, beterraba, repolho, couve, couve flor, tomate, cebolinha, salsa, morango, batata doce, mandioca, alecrim, manjerona, manjericão, abóbora, moranga japonesa, capim cidreira e funcho. Em outubro foram plantadas mandioca e pimentão.

Em janeiro de 2018 foi realizada adubação do solo com esterco de aves e bovinos e semeadas as seguintes culturas: feijão de metro, milho pipoca e pimentão e colhidas as morangas japonesas e tomates. Em fevereiro foram semeadas cenoura, rabanete, alface, espinafre, couve manteiga e foram plantadas roseiras e cravo-de-defunto. Nesse mês foram colhidos os tomates e em março foi realizada a colheita de mandioca, pimentão e novamente do tomate.

No mês de março foi realizado um encontro na escola para tratar das atividades que a horta pode proporcionar nas mais diversas áreas do conhecimento. Para exemplificar as diferentes possibilidades de uso da horta pelos professores, nesse encontro a turma convidada a trabalhar com a horta foi a turma de $2^{\circ}$ ano na disciplina de História. Em julho foram colhidas mandioca, milho pipoca e batata doce, já em agosto foram colhidas alface e cenoura.

A manutenção da horta é realizada por alunos, professores e funcionários da escola, com o auxílio de alunos do curso de Engenharia Agrícola da Universidade Federal de Santa Maria - Campus Cachoeira do Sul e a coordenadora do projeto intitulado "Horta viva na escola", da mesma universidade.

\section{Resultados e discussão}

O espaço disponibilizado pela Escola Estadual de Ensino Médio Ruy Barbosa para a implantação da horta media 88 $\mathrm{m}^{2}$ (onze metros de comprimento por oito metros de largura). Era uma área com desnível e muitos caules e raízes de árvores, havendo a necessidade de muito trabalho até ser possível montar os canteiros e fazer o cultivo das plantas. Devido a isso, desde o início das atividades de implantação da horta, em agosto de 2017, ficou evidente a importância da comunidade na realização de atividades da escola. A comunidade se fez presente quando a área da horta foi cercada, nas atividades de gradagem e na montagem dos canteiros (Figuras 1 e 2).

Figura 1 - Horta da Escola Estadual de Ensino Médio Ruy Barbosa, Novo Cabrais - RS. a) Gradagem com o auxílio de trator emprestado por vizinho da escola. b) Preparo dos canteiros

(a)

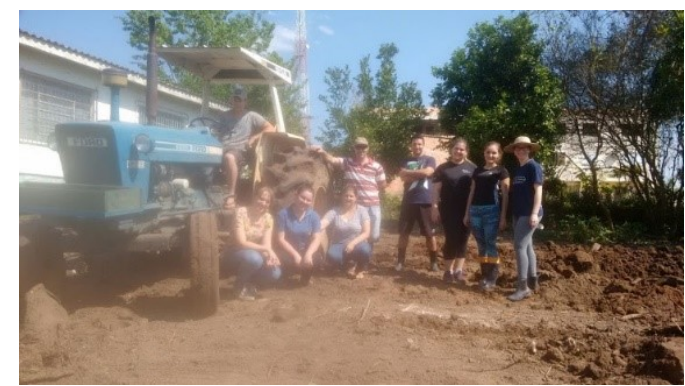

(b)

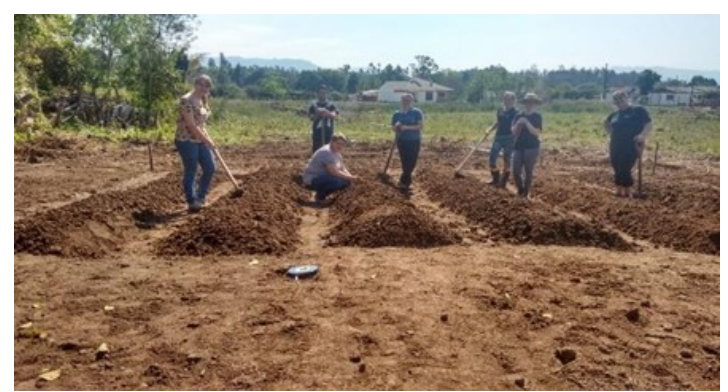

Fonte: Autores 
Figura 2 - a e b) Preparo dos canteiros na horta da Escola Estadual de Ensino Médio Ruy Barbosa, Novo Cabrais - RS

(a)

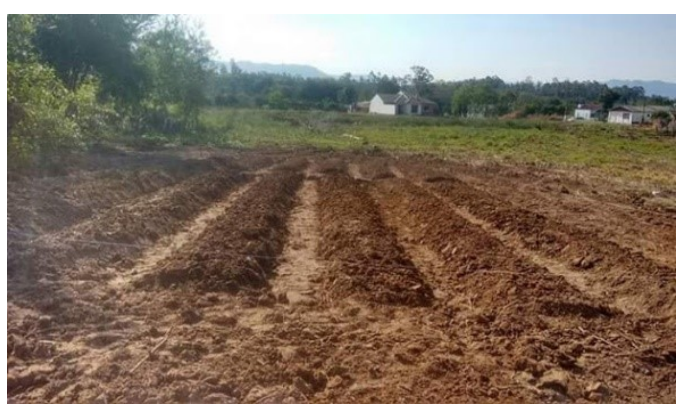

(b)

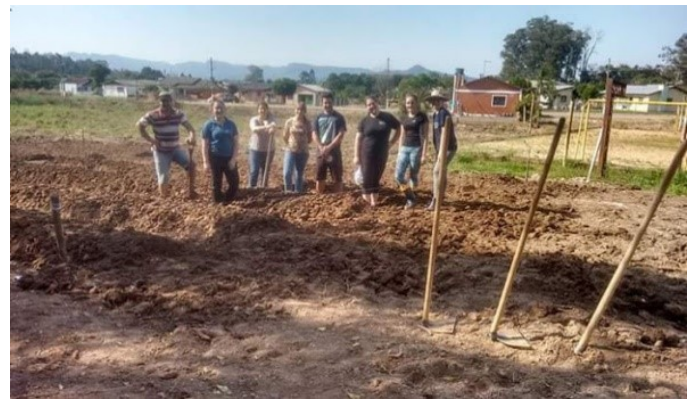

Fonte: Autores

Após cercar a horta, realizar a gradagem e a montagem da horta, foram realizadas a semeadura e o plantio das hortaliças (Figura 3a). No entanto, a produção das primeiras culturas implantadas, em setembro e outubro de 2017 , não foi satisfatória, mas auxiliou na percepção de que o solo da horta necessitava de adubação. Por isso, em janeiro de 2018 foi realizada adubação do solo com esterco de aves e bovinos. Posteriormente foram cultivadas as seguintes espécies: feijão de metro, milho pipoca e pimentão e colhidas as morangas japonesas, tomates, cenoura, rabanete, alface, espinafre, e couve manteiga (Figura 3b).

Também em janeiro de 2018 foram plantadas roseiras e cravo-de-defunto para auxiliar na polinização das espécies de hortaliças atraindo polinizadores. Ainda, o cravo-de-defunto é um repelente natural de insetos e a roseira auxilia na identificação de formigas cortadeiras e outras pragas quando elas estão iniciando o ataque à horta.

Figura 3 - Horta da Escola Estadual de Ensino Médio Ruy Barbosa, Novo Cabrais - RS. a) Plantio das culturas na horta em outubro de 2017. b) Manejo da horta e plantio de culturas em março de 2018, após a aplicação de esterco bovino e de aves realizada em janeiro de 2018

(a)

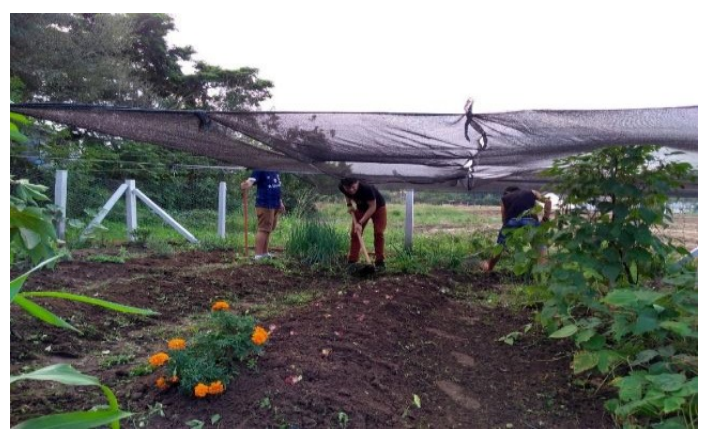

(b)

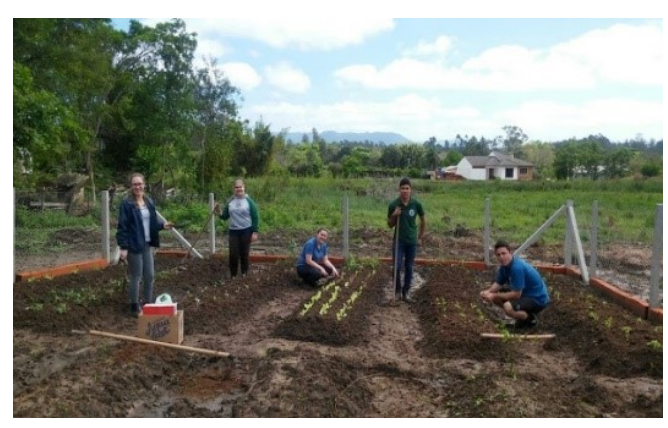

Fonte: Autores

Em março de 2018 foi realizado um encontro na escola para exemplificar quais atividades que podem ser desenvolvidas na horta, proporcionando a relação entre as diversas áreas do conhecimento. Esse momento foi esclarecedor aos professores que utilizarão a horta como um laboratório vivo para trabalhar a interdisciplinaridade nas mais diversas áreas. Foram discutidas as possibilidades de atividades e áreas do conhecimento (Figura 4). 
Figura 4 - Horta da Escola Estadual de Ensino Médio Ruy Barbosa, Novo Cabrais - RS. a) Alunos em atividade de manejo da horta durante atividade extra classe em março de 2018. b) Atividade realizada durante a aula da disciplina de História, em março de 2018.

(a)

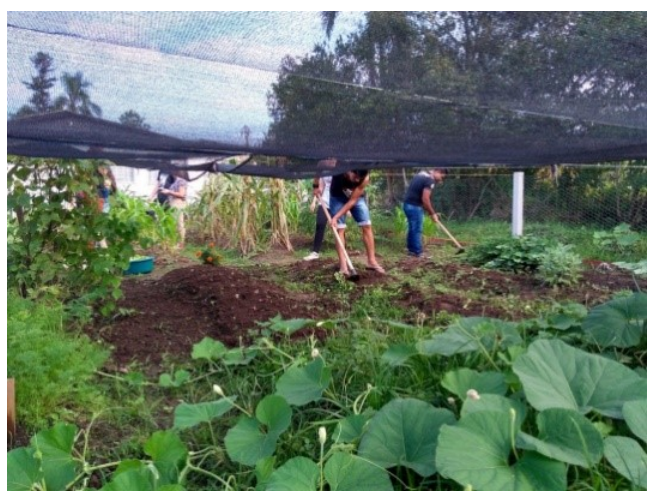

(b)

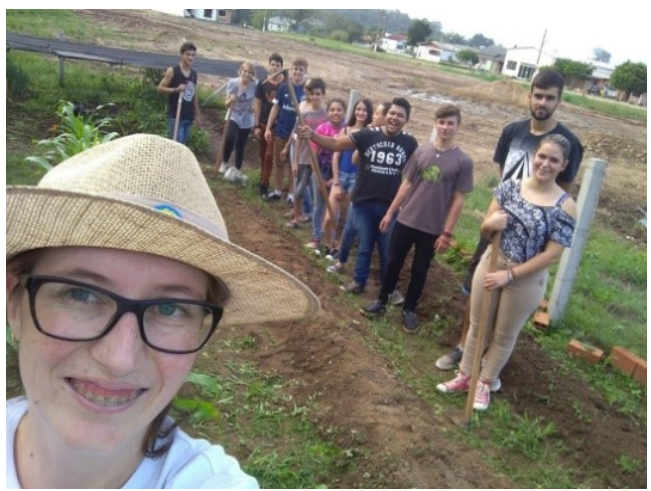

Fonte: Autores.

Desde a primeira colheita, a produção da horta é utilizada na alimentação dos alunos, professores e funcionários da escola (Figura 5).

Figura 5 - Horta da Escola Estadual de Ensino Médio Ruy Barbosa, Novo Cabrais - RS. a) Colheita de hortaliças para a merenda na escola. b) Colheita do milho pipoca

(a)

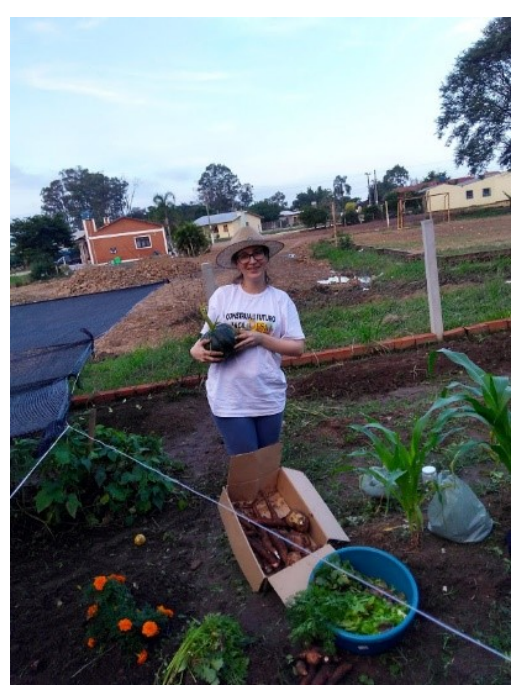

(b)

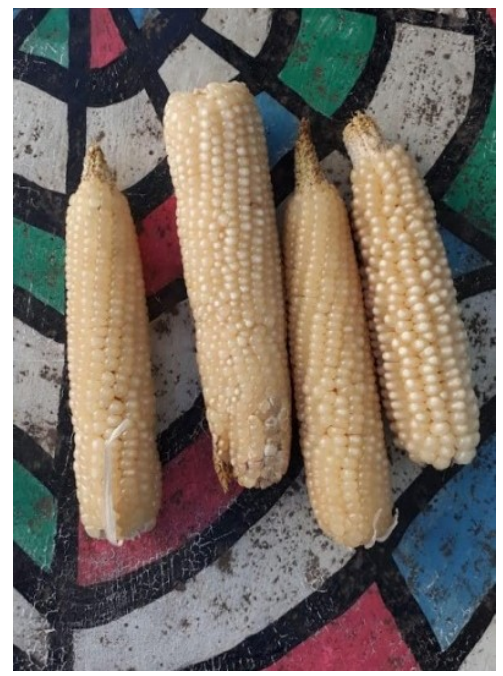

Fonte: Autores.

Para garantir o sucesso na produção da horta a escola permanece em contato com os integrantes do projeto "Horta viva na escola" da Universidade Federal de Santa Maria - Campus Cachoeira do Sul. Isso garante a manutenção da horta com culturas respeitando suas sazonalidades e livres de pragas e doenças, seguindo sempre os princípios da sustentabilidade. Assim, a Escola Estadual de Ensino Médio Ruy Barbosa terá sempre um espaço laboral para as diferentes disciplinas cursadas pelos alunos da escola.

Assim como em estudo realizado por Campioto (2015), o presente trabalho implantou uma horta em escola de ensino médio e a partir da implantação da horta observou-se que a horta é uma ferramenta muito eficaz na formação integral do estudante. Entretanto, é responsabilidade da de todos que estão envolvidos no processo de aprendizagem, os alunos, os 
professores, a direção, os funcionários e a comunidade em geral buscar atividades relacionadas ao ambiente da horta e aos conteúdos que devem ser estudados pelos alunos.

\section{Conclusão}

Com a realização do presente trabalho destaca-se que o uso da horta como laboratório vivo possibilita aos professores de diversas disciplinas trabalhar em conjunto, proporcionando aos alunos diferentes conhecimentos.

A implantação da horta estimula o aprendizado dos alunos nas diferentes áreas do conhecimento, além de despertar no aluno um ponto de vista diferente ao consumir e produzir alimentos saudáveis, sem agrotóxicos, permitindo que os conhecimentos adquiridos sejam levados para a sociedade.

\section{Referências}

BRASIL. Ministério da Educação. Secretaria de Educação Média e Tecnológica. Parâmetros Curriculares Nacionais. Ensino Médio. Brasília: Ministério da Educação, 2002.

CAMPIOTO, G.M.C. Horta didática: uma abordagem interdisciplinar. [monography]. Viçosa: Departamento de Química/UFV; 2015.

COGO, G. P.; DOLIANITIS, B. M.; ANSCHAU, J. R.; MORAES, R. S.; ZAPPE, J. A.; FRESCURA, K. D.; FRESCURA, V. D. Horta Viva na Escola. In: Trabalhos [recurso eletrônico] da Mostra de Projetos da UFSM-CS [internet]; 2017; Cachoeira do Sul, Brasil. 2017. Disponível em http://w3.ufsm.br/cachoeira/images/2017/2017.2/EBook_Trabalhos_da_Mostra_de_Projetos_da_UFSM-CS.pdf.

FAZENDA, I. C. A . O que é interdisciplinaridade? São Paulo: Cortez, 2008.

MORIN, E. Os saberes necessários à Educação do futuro. 2nd ed. São Paulo: Cortez, 2000.

PAVIANI, J. Interdisciplinaridade: conceitos e distinções. 2nd ed. Caxias do Sul. RS: Educs, 2008. 